\title{
IN VIVO MUSCLE FORCE-LENGTH BEHAVIOR DURING STEADY-SPEED HOPPING IN TAMMAR WALLABIES
}

\author{
ANDREW A. BIEWENER ${ }^{1}, *$, DAVID D. KONIECZYNSKI ${ }^{1}$ AND RUSSELL V. BAUDINETTE ${ }^{2}$ \\ ${ }^{1}$ Department of Organismal Biology and Anatomy, The University of Chicago, Chicago, IL 60637, USA and \\ ${ }^{2}$ Department of Zoology, University of Adelaide, Adelaide, South Australia 5000, Australia \\ *e-mail: a-biewener@uchicago.edu
}

Accepted 3 March; published on WWW 12 May 1998

\begin{abstract}
Summary
Moderate to large macropodids can increase their speed while hopping with little or no increase in energy expenditure. This has been interpreted by some workers as resulting from elastic energy savings in their hindlimb tendons. For this to occur, the muscle fibers must transmit force to their tendons with little or no length change. To test whether this is the case, we made in vivo measurements of muscle fiber length change and tendon force in the lateral gastrocnemius (LG) and plantaris (PL) muscles of tammar wallabies Macropus eugenii as they hopped at different speeds on a treadmill. Muscle fiber length changes were less than $\pm 0.5 \mathrm{~mm}$ in the plantaris and $\pm 2.2 \mathrm{~mm}$ in the lateral gastrocnemius, representing less than $2 \%$ of total fiber length in the plantaris and less than $6 \%$ in the lateral gastrocnemius, with respect to resting length. The length changes of the plantaris fibers suggest that this occurred by means of elastic extension of attached cross-bridges. Much of the length change in the lateral gastrocnemius fibers

speed in either muscle $(P>0.05)$, despite a 1.6-fold increase in muscle-tendon force between speeds of 2.5 and $6.0 \mathrm{~m} \mathrm{~s}^{-1}$. Length changes of the PL fibers were only $7 \pm 4 \%$ and of the LG fibers $34 \pm 12 \%$ (mean \pm S.D., $N=170$ ) of the stretch calculated for their tendons, resulting in little net work by either muscle (plantaris $0.01 \pm 0.03 \mathrm{~J}$; gastrocnemius $-0.04 \pm 0.30 \mathrm{~J}$; mean \pm S.D.). In contrast, elastic strain energy stored in the tendons increased with increasing speed and averaged 20-fold greater than the shortening work performed by the two muscles. These results show that an increasing amount of strain energy stored within the hindlimb tendons is usefully recovered at faster steady hopping speeds, without being dissipated by increased stretch of the muscles' fibers. This finding supports the view that tendon elastic saving of energy is an important mechanism by which this species is able to hop at faster speeds with little or no increase in metabolic energy expenditure.
\end{abstract} occurred at low force early in the stance phase, with generally isometric behavior at higher forces. Fiber length changes did not vary significantly with increased hopping
Key words: muscle fibre strain, force, sonomicrometry, elastic energy, hopping, tammar wallaby, Macropus eugenii.

\section{Introduction}

Red kangaroos Macropus rufus (Dawson and Taylor, 1973), tammar wallabies Macropus eugenii (Baudinette et al. 1992) and possibly other large macropodids appear unique in their ability to increase their speed of locomotion with little or no increase in metabolic energy expenditure. In contrast, metabolic energy expenditure generally increases linearly with speed for the terrestrial locomotion of other mammals and birds (Taylor et al. 1982). The storage and recovery of elastic strain energy in the hindlimb tendons of kangaroos and wallabies has been proposed as the key mechanism underlying the ability of these animals to accomplish this feat (Alexander and Vernon, 1975; Bennett and Taylor, 1995; Biewener and Baudinette, 1995; Cavagna et al. 1977). Although elastic savings probably also reduce metabolic energy expenditure during running, trotting and galloping of other mammals and birds (Cavagna et al. 1977), they appear to provide a more substantial saving of metabolic energy for moderate to large macropods. This is surprising given that the muscles, tendons and ligaments of ungulates (Biewener, 1998; Dimery and Alexander, 1985; Dimery et al. 1986a,b) are considered to be more highly specialized for elastic energy savings than are the tendons and muscles of macropods (Ker et al. 1986). However, despite their longer tendons and shorter-fibered muscles, metabolic energy expenditure increases linearly with speed in ungulates, as it does in animals with less-specialized limbs (Taylor et al. 1982).

In a previous study (Biewener and Baudinette, 1995), we showed, by means of direct measurements of muscle-tendon forces, that the in vivo strains developed within the principal hindlimb tendons of tammar wallabies during hopping provided sufficient strain energy storage to enable a saving of as much as $45 \%$ in metabolic energy expenditure (assuming an efficiency of 0.25 for muscle work that would otherwise be required to power the animal's hopping). For this to occur, 


\section{A. A. Biewener, D. D. Konieczynski And R. V. Baudinette}

however, strain energy stored within the tendon must be usefully recovered when the tendon recoils. Unless the muscles maintain sufficient stiffness during tendon recoil, strain energy stored within the tendon might otherwise be dissipated by stretch of the muscles' fibers. On the basis of the in situ measurements of 'in series' muscle-tendon stiffness within the medial gastrocnemius of the thylogale wallaby Thylogale billardierii, Griffiths (1989) argued that the relatively low stiffness of the muscle (40\% of its tendon's stiffness) precluded storage and recovery of strain energy in the tendon as a mechanism to account for the absence of an increase in metabolic energy expenditure at faster hopping speeds.

Because our earlier measurements of muscle-tendon force did not address how fiber length change was related to force development, we could not confirm whether strain energy stored within the hindlimb tendons was usefully recovered or whether it was dissipated by excessive stretch of the muscle fibers. Therefore, the goal of the present study was to relate measurements of muscle-tendon force to simultaneous measurements of muscle fiber length change by means of sonomicrometry in order to determine the in vivo force-length behavior of the muscles during steady-speed hopping. We use these measurements to resolve whether tendon elastic savings provide a mechanism that can help to explain the decoupling of metabolic cost from increased hopping speed.

\section{Materials and methods}

Animals

Four adult tammar wallabies Macropus eugenii (three male and one female, ranging from 3.62 to $5.82 \mathrm{~kg}$ in body mass) were trained to hop on a motor-driven treadmill $(2.5 \mathrm{~m} \times 0.5 \mathrm{~m}$ bed) at speeds ranging from 2.5 to $6.0 \mathrm{~m} \mathrm{~s}^{-1}$. The animals were obtained from a breeding colony maintained at Flinders University, South Australia, Australia, and housed in outdoor pens located adjacent to the research laboratory during training, but were housed in indoor pens following surgery. We reported data for the forces and energy stored in the hindlimb tendons of three of the four wallabies in a previous paper (Biewener and Baudinette, 1995). Data for muscle fiber length change in relation to force development are reported here, together with those obtained from an additional animal.

\section{Sonomicrometry and electromyography recordings}

All transducers were sterilized ( $12 \mathrm{~h}$ ultraviolet illumination and $1 \mathrm{~h}$ immersion in a germicide/disinfectant solution) and implanted using sterile surgical techniques under general anesthesia (isofluorane), following acceptable veterinary guidelines. Sonomicrometer disc electrodes ( $2 \mathrm{~mm}$, Triton Inc.) were implanted into the bellies of the lateral gastrocnemius and plantaris muscles by means of incisions made in the skin overlying these two muscles. Access to the plantaris required making an incision through the aponeurosis between the lateral and medial heads of the gastrocnemius to expose the underlying surface of the muscle. This incision was sutured closed following implantation of the transducers in the plantaris.

Prior to their implantation, a support holder (made from $0.2 \mathrm{~mm}$ diameter stainless-steel wire) was glued using epoxy adhesive to the sonomicrometer electrodes (Fig. 1B). The holder was designed to anchor the electrode into position within the muscle via suture ties (4-0 silk) made through the wire loops into the muscle's fascia. This structure allowed the electrodes to be oriented at various angles to match the muscle fibers' pennation angle. The electrodes were inserted to a depth of approximately $4 \mathrm{~mm}$ beneath the surface of the muscle by using small sharp-pointed scissors to puncture the fascia and create an opening parallel to the muscle fibers. The incision was sutured closed after implanting the electrode to help secure its position within the muscle. Examination of the muscles after recordings had been completed showed that the sonomicrometer electrodes were securely anchored in place by a fibrous response of the muscle. Morphological data for the muscles and tendons of the four animals are presented in Table 1.

We chose to implant sonomicrometer electrodes in the lateral head, rather than the medial head, of the gastrocnemius muscle in order to minimize the number of surgical wounds and for relative ease of access. In the case of the unipennate lateral gastrocnemius (which has a mean fiber angle of $28^{\circ}$ that was measured by digitizing a video image of the muscle perpendicular to the fiber plane at $10 \times$ magnification using a CCD camera mounted on a Zeiss Axioplan dissecting microscope and MTV software, DataCrunch Inc.), it was possible to implant a pair of sonomicrometer electrodes by exposing the superficial and deep surfaces of the muscle

Table 1. Morphological data for the muscles and their tendons (data for wallabies 2, 3 and 4 are from Biewener and Baudinette, 1995)

\begin{tabular}{|c|c|c|c|c|c|c|c|c|c|}
\hline & \multirow[b]{2}{*}{$\begin{array}{l}\text { Body mass } \\
(\mathrm{kg})\end{array}$} & \multicolumn{4}{|c|}{ Plantaris } & \multicolumn{4}{|c|}{ Lateral gastrocnemius } \\
\hline & & $\begin{array}{l}\text { Mass } \\
(\mathrm{g})\end{array}$ & $\begin{array}{c}\text { Fiber length, } \\
L_{\mathrm{f}}(\mathrm{mm})\end{array}$ & $\begin{array}{c}\text { Tendon length } \\
(\mathrm{mm})\end{array}$ & $\begin{array}{l}\text { Tendon area } \\
\left(\mathrm{mm}^{2}\right)\end{array}$ & $\begin{array}{l}\text { Mass } \\
(\mathrm{g})\end{array}$ & $\begin{array}{c}\text { Fiber length, } \\
L_{\mathrm{f}}(\mathrm{mm})\end{array}$ & $\begin{array}{l}\text { Tendon length } \\
(\mathrm{mm})\end{array}$ & $\begin{array}{l}\text { Tendon area } \\
\left(\mathrm{mm}^{2}\right)\end{array}$ \\
\hline 1 & 4.33 & 21.47 & 15.8 & 304 & 9.16 & 12.45 & 17.7 & 168 & 7.63 \\
\hline 2 & 5.42 & 24.93 & 19.5 & 310 & 10.15 & 12.80 & 20.2 & 173 & 9.99 \\
\hline 3 & 5.82 & 30.70 & 16.3 & 295 & 10.72 & 14.81 & 17.9 & 167 & 8.44 \\
\hline
\end{tabular}




\section{In vivo muscle force-length changes during wallaby hopping 1683}

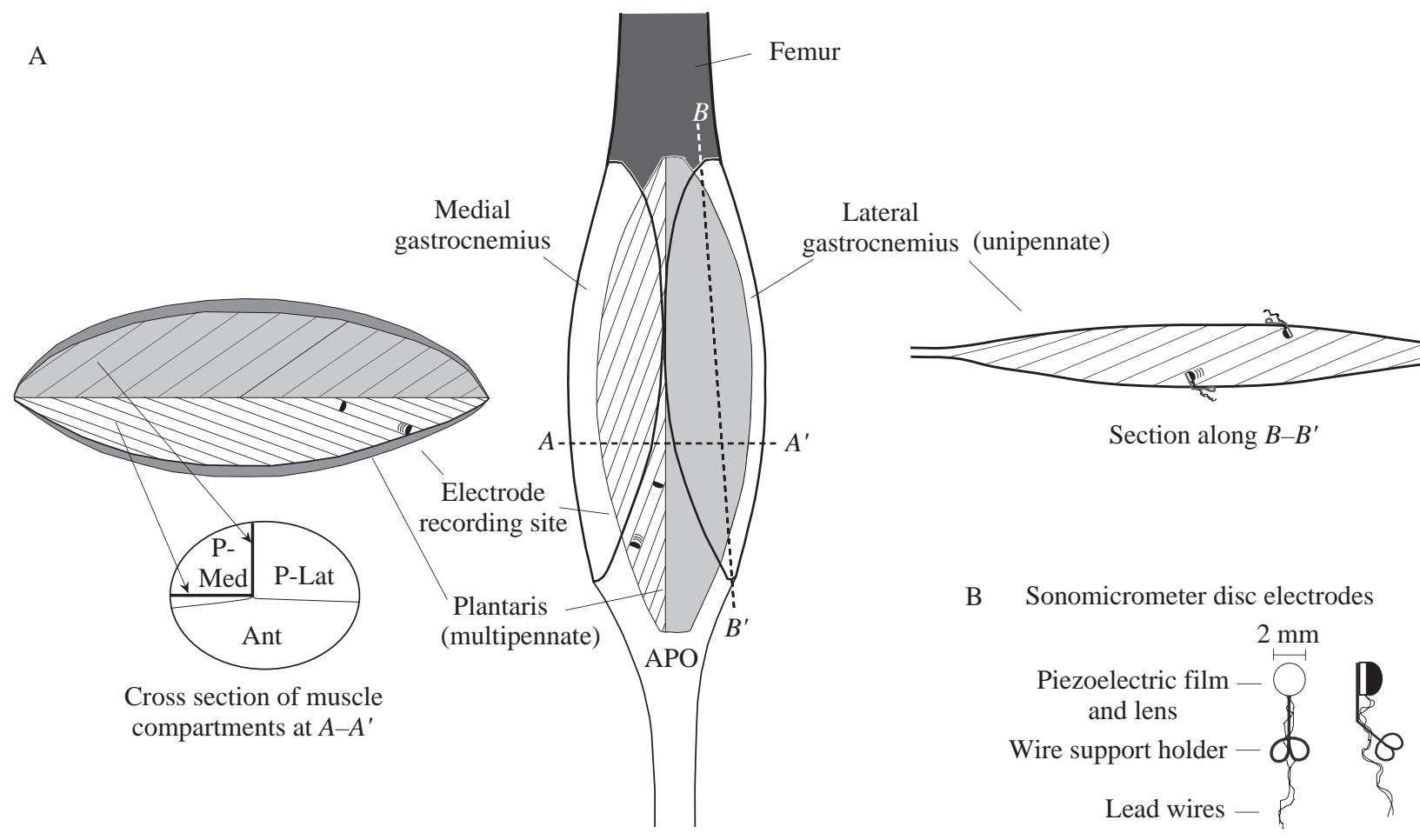

Fig. 1. (A) Diagram illustrating the implantation sites of the disc sonomicrometer electrodes in the unipennate lateral head of the gastrocnemius muscle and the postero-medial (P-Med) compartment of the deeper multipennate plantaris muscle. Access to superficial fibers of the plantaris P-Med compartment (hatched, showing fiber orientation) was achieved by cutting open and reflecting back the aponeurosis (APO, depicted as being transparent) between the medial and lateral heads of gastrocnemius. Section views of the muscles' fiber architecture are shown on the left for the plantaris (P-Lat, postero-lateral compartment; Ant, anterior compartment) and on the right for the lateral gastrocnemius. (B) Disc electrodes mounted on the stainless-steel wire support holder used to orient the electrodes along the fiber axis and to anchor them via sutures at the muscle's surface (holders are depicted in A for the lateral gastrocnemius electrodes but not for the plantaris electrodes).

(Fig. 1A). However, this was not possible for the multipennate plantaris (mean fiber angle $35^{\circ}$, based on an average obtained from digitized video images at six locations within the muscle) because of its deeper location. Instead, we selected a superficial portion of the plantaris beneath its postero-medial (P-Med) surface (Fig. 1A) that allowed a pair of electrodes to be implanted parallel to the muscle's fibers. Fibers in this region of the muscle run obliquely at an angle from the muscle's surface to fascial sheets separating the P-Med compartment (hatched to show fiber orientation in Fig. 1A) from the postero-lateral (PLat, shaded in Fig. 1A) and anterior (Ant) compartments. Local recordings of fiber length change at these locations in the two muscles are assumed to be representative of those for active regions of the muscle as a whole. Electromyographic recordings (see below) made at the same sites were used to confirm that the length recordings were those of active muscle fibers. There are no indications that the sonomicrometry electrodes affect the local contractile function of muscle fibers, and such effects are assumed here to be negligible.

Sonomicrometry recordings of length change are based on measurements of the 'transit time' of an ultrasonic $(5 \mathrm{MHz})$ sound pulse that travels from an emitting to a receiving piezoelectric crystal (forming an electrode pair). We assumed a pulse velocity of $1540 \mathrm{~m} \mathrm{~s}^{-1}$ for vertebrate skeletal muscle
(Goldman and Richards, 1954; Goldman and Hueter, 1956; Hatta et al. 1988), which requires a $+2.7 \%$ correction (length increase) of the Triton sonomicrometer's length calibration (based on a value of $1500 \mathrm{~m} \mathrm{~s}^{-1}$ for water at $37^{\circ} \mathrm{C}$ ). Length signals were also offset by $+0.74 \mathrm{~mm}$, to account for the higher velocity of sound propagation through the epoxy lens of the electrodes versus the intervening muscle tissue, and corrected for a $5 \mathrm{~ms}$ phase delay introduced by the sonomicrometer's low-pass filter (Marsh et al. 1992). Changes in muscle density during contraction that might alter the speed of sound transmission (and hence, the calibration of length) have been found to be small (less than $5 \%$ in the worst case; Griffiths, 1987; Hatta et al. 1988). In general, $5 \%$ errors in length are likely to be far smaller than those obtained using conventional kinematic methods as well as by other length-transducing techniques (Loeb et al. 1985). The crystals were implanted with a spacing of $12-15 \mathrm{~mm}$ to avoid problems associated with the dissipation of signal energy strength at longer lengths.

Fractional muscle fiber length changes $\left(\Delta L_{\text {fract }}\right)$ were established on the basis of a value for resting length measured between a pair of electrodes $\left(L_{\mathrm{sono}}\right)$ at the time of surgery when the animal was anesthetized $\left(\Delta L_{\text {fract }}=\Delta L_{\mathrm{s}} / L_{\mathrm{sono}}\right.$, where $\Delta L_{\mathrm{s}}$ is the length change measured between the two electrodes during locomotor activity). $\Delta L_{\text {fract }}$ was then used to establish total 


\section{A. A. Biewener, D. D. Konieczynski And R. V. Baudinette}

muscle fiber length changes $\Delta L_{\mathrm{f}}\left(\Delta L_{\mathrm{f}}=\Delta L_{\mathrm{fract}} \times L_{\mathrm{f}}\right.$, where $L_{\mathrm{f}}$ is the resting fiber length of the muscle determined by post-mortem dissection). The distance between sonomicrometry electrodes was typically $70 \%$ of the muscle fiber's total length. Both the shortening (positive) work and the net work (area contained within a work loop) of the muscles were determined on the basis of changes in total fiber length versus muscle force.

Fine-wire bipolar electromyography (EMG) electrodes were then implanted into the muscles at locations immediately adjacent to the sonomicrometer electrodes. The electrodes consisted of insulated silver wires $(0.1 \mathrm{~mm}$ o.d., California Fine Wire) twisted along their length, with the tips bared along $0.5 \mathrm{~mm}$ at their ends and spaced $2.0 \mathrm{~mm}$ apart. The ends were bent back to form hooks and inserted into the muscle belly using a 23 gauge hypodermic needle (Basmajian and De Luca, 1985; Loeb and Gans, 1986). The electrodes were sutured to fascia at their exit point from the muscle, leaving a small loop to ensure that they could move with the muscle as it contracted to reduce movement artifact in the EMG signal.

\section{Buckle transducers and force recordings}

'E'-shaped stainless-steel buckle transducers, equipped with a metal foil strain gauge (type FLA-1, Tokyo Sokki Kenkyujo) bonded to the central arm (Fig. 2A; for details, see Biewener and Baudinette, 1995), were attached to the plantaris and gastrocnemius tendons by making a lateral incision through the skin to expose the underlying Achilles tendon. The peritendinous fascia was then cut longitudinally to separate the plantaris and gastrocnemius (medial and lateral) tendons. The buckles were spaced along the tendons so that the central arms of adjacent transducers did not come into contact (Fig. 2B). Small ties (4-0 silk) to the tendon were made through small holes located on the buckle's arms (Fig. 2A) to prevent the buckles from shifting position on the tendons. Each transducer was calibrated with a nylon cord before and after use to verify that no change in sensitivity occurred during the experimental period.

All lead wires were then passed subcutaneously to a small plastic connector (Amphenol, series 222) located anterior to the animal's hip. The lead wires were soldered to pins that were inserted into the connector and sealed with RTV silicone rubber adhesive (Dow Corning). Silk suture (0 gauge) was used to secure the connector to the animal's skin and to close all wounds. An analgesic (10 mg of Flunixin, Schering-Plough)
A

Side

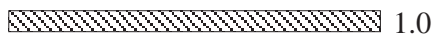

Fig. 2. (A) Schematic design of the stainless-steel buckle force transducer implanted on the tendons of the plantaris (PL) and lateral and medial gastrocnemius (LG and $\mathrm{MG}$ ) muscles. Measurements are in millimeters. (B) Implantation sites of the tendon buckles in the hindlimb of a wallaby [buckle force recordings of the flexor digitorum longus (FDL) were obtained in some animals for a related study (Biewener and Baudinette, 1995) but are not presented or discussed here because no sonomicrometer recordings of muscle fiber length change were made of the FDL]. (C) Representative in situ force calibrations obtained for the buckles immediately following completion of the experimental recordings. Leastsquares regressions of force versus buckle voltage output yielded dynamic calibrations during the rise (filled symbols) and fall (open symbols) in applied force. An average regression slope was used to establish a calibration of force.
Top

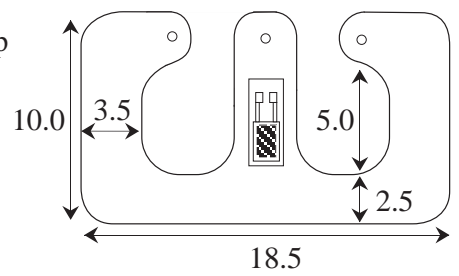

B

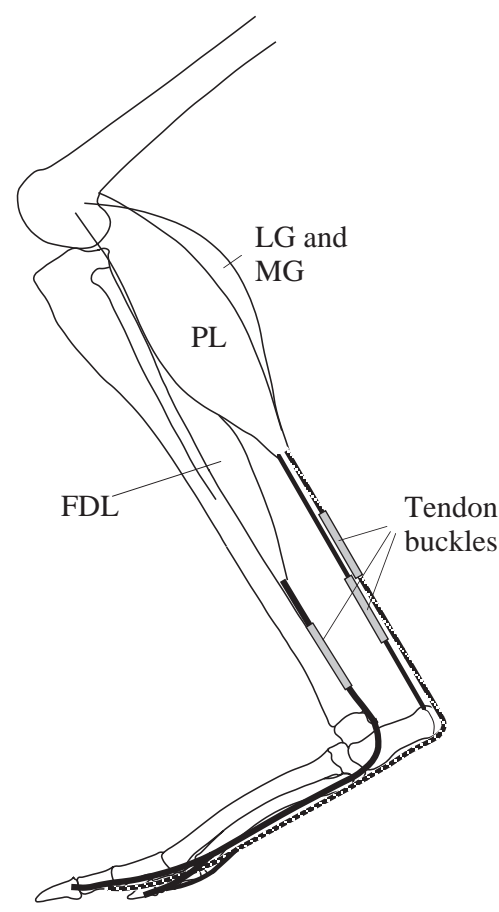

$\mathrm{C}$

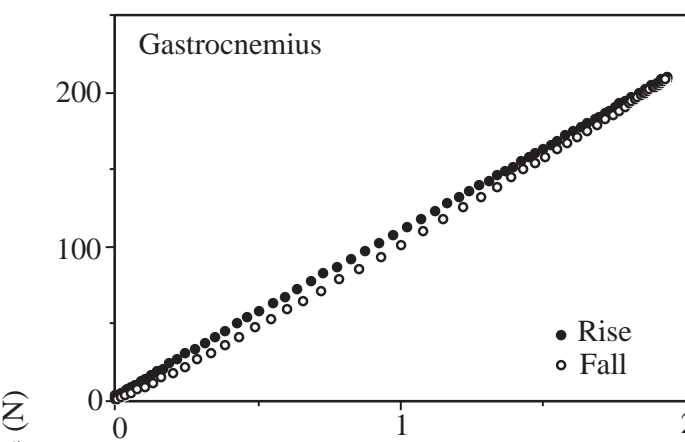

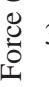

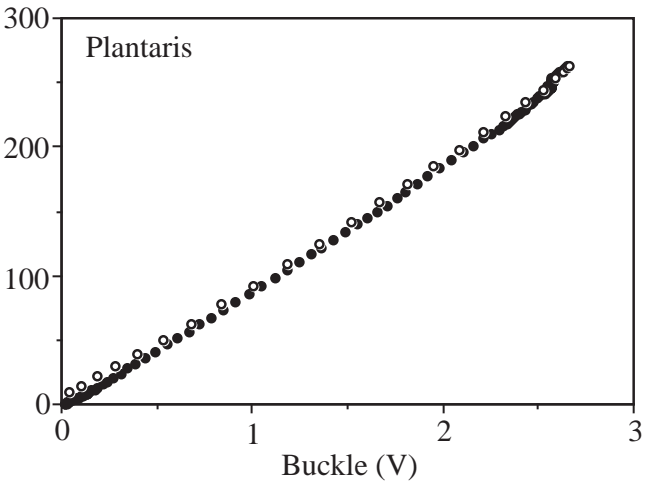


and an antibiotic (50000 i.u. of procaine penicillin, Glaxovet) were administered following surgery.

\section{Experimental and calibration procedures}

Following a $24 \mathrm{~h}$ period of recovery, recordings of muscle EMG activity, force and fiber length change were made while the animals hopped on the treadmill. The EMG signals were amplified (1000×) and bandpass-filtered $30-1000 \mathrm{~Hz}$ (Grass P511 amplifier). The force buckle signals were conditioned using a bridge amplifier (Vishay, model 2230). These signals, together with the outputs of the sonomicrometry amplifier, were sampled at $1000 \mathrm{~Hz}$ via a Metrabyte Dash-16F A/D converter using custom-developed Asyst software (Keithley Instruments) and stored for subsequent analysis. Because the EMG signals were filtered and sampled at $1000 \mathrm{~Hz}$, the analysis of EMG timing relative to force development had a temporal resolution of $2 \mathrm{~ms}$. Recordings were made over a 2 day period. Measurements of muscle-tendon force and fiber length change were typically based on an analysis of data sampled for 14 cycles or more for each animal at each hopping speed.

After the experimental recordings had been completed, the animals were killed ( $900 \mathrm{mg}$ of pentobarbitone sodium injected intravenously) and their tendons and muscles dissected free for morphological measurements, to verify the position and alignment of the sonomicrometer electrode pairs, and for calibration of the force buckles on the tendons. Misalignment of the electrodes to the muscle fiber axis $(\alpha)$ resulted in worstcase errors of $1 \%\left\{[1-(1 / \cos \alpha)] \times 100 ; \alpha=8^{\circ}\right\}$ and were therefore ignored.

Details of the calibration procedure used to obtain a dynamic in situ calibration of the force buckles on the tendons are described elsewhere (Biewener and Baudinette, 1995). Briefly, the tendons were cut free from the muscle and their ends clamped and frozen with liquid nitrogen prior to imposing a series of cyclical loads via a force transducer. In general, little if any sign of tendon wear or fibrous tissue response was observed following the experimental recordings. The outputs of the force transducer and the tendon buckle were sampled at $100 \mathrm{~Hz}$ and stored on computer. Regressions of force versus voltage output of the buckle transducer (Fig. 2C) yielded dynamic calibrations of the rise and fall in force. An average of the two slopes was used to establish the calibration for the force buckle. Correlation coefficients $\left(r^{2}\right)$ greater than 0.97 were obtained for all regression calibrations, with $95 \%$ confidence intervals being less than $3 \%$ of the regression slope. As there was little hysteresis, the regression slopes for the rise and fall in force differed by less than $3.5 \%$ in all cases.

\section{Measurements of muscle work and estimates of limb contact time, duty factor and tendon elastic energy}

Muscle fiber shortening (positive) work was determined by integrating $1 \mathrm{~ms}$ sample intervals for all periods of the contraction cycle during which the muscle fiber shortened and exerted measurable force (work $=$ force $\times$ fiber shortening).
Lengthening (negative) work was determined similarly by integrating all sample intervals during which the muscle fiber lengthened and exerted force. The net work performed by the muscle was calculated by summing the positive and negative work for each contraction cycle. The net work is equivalent to the area contained within a muscle work loop (Josephson, $1985)$. We estimated limb contact time $\left(T_{\mathrm{c}}{ }^{*}\right)$ and hindlimb duty factor $\left(T_{\mathrm{c}}{ }^{*} /\right.$ stride period) using the duration of force generation by the gastrocnemius muscle. For the observed range of hopping speeds, the gastrocnemius muscle exerts force over the entire period of limb contact, with little evidence of force generation prior to the onset of limb contact with the ground (Biewener and Baudinette, 1995). Consequently, gastrocnemius force duration represents a good estimate of limb contact time and is relevant to a consideration of how increases in the rate of force development are likely to influence metabolic cost.

Tendon elastic energy ( $E_{\text {elas }}$ ) was calculated on the basis of the method reported in Biewener and Baudinette (1995), using the equation:

$$
E_{\text {elas }}=0.5\left(\sigma^{2} / E\right) V_{\mathrm{t}} \times 0.93,
$$

where $\sigma$ is the stress (MPa) calculated to act in the tendon, $E$ is the tendon's elastic modulus ( $1.0 \mathrm{GPa})$ based on values reported for the range of stresses developed during hopping (Bennett et al. 1986; Ker, 1981; Shadwick, 1990), $V_{\mathrm{t}}$ is the tendon volume $\left(\mathrm{m}^{3}\right)$ and 0.93 represents the fraction of energy recovered relative to the amount stored during stretch of the tendon (resiliency), also based on the above studies.

Unless otherwise noted, all values are presented as the mean \pm S.D.

\section{Results}

In vivo recordings of muscle force and length change

Representative recordings of in vivo force and fiber length change in the plantaris and gastrocnemius muscles are shown in Fig. 3 for a wallaby hopping at $4.5 \mathrm{~m} \mathrm{~s}^{-1}$. Although changes in fiber length of $3.0 \mathrm{~mm}$ or greater were observed in the two muscles, most of the change in length occurred during the swing phase of the stride, particularly when the muscles shortened and subsequently re-extended as the foot left the ground (Fig. 3). In contrast, little change in length was observed in either muscle (PL $<1.0 \mathrm{~mm}, \mathrm{LG}<2.0 \mathrm{~mm}$ ) during the stance phase of the stride, particularly when the muscles were generating more than $33 \%$ of maximum force (length change $<0.8 \mathrm{~mm}$ ). These values correspond to fractional changes of less than \pm 0.02 of fiber length ( $\Delta L_{\text {fract }}$ ) for the plantaris and less than \pm 0.06 for the lateral gastrocnemius of this particular wallaby (wallaby 2 ) hopping at $4.5 \mathrm{~m} \mathrm{~s}^{-1}$. Similar fractional length changes were observed in the other two animals for which measurements of these muscles were obtained (Table 2). Most of the shortening observed in the lateral gastrocnemius occurred early in support when the muscle was generating less than $33 \%$ of its maximum force. 

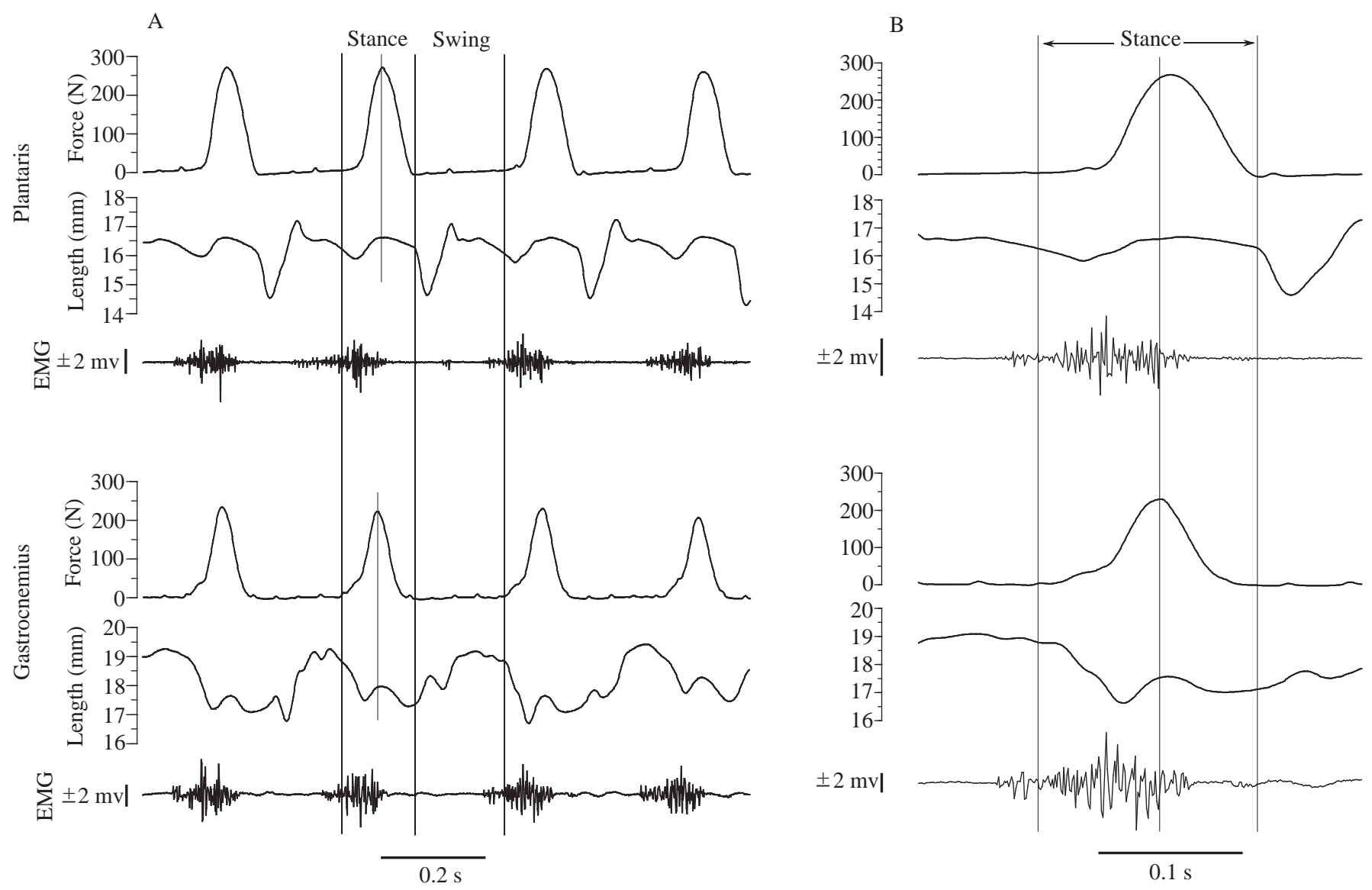

Fig. 3. (A) Representative in vivo force, sonomicrometer fiber-length and EMG recordings obtained from the plantaris and gastrocnemius muscles for four cycles of wallaby 2 hopping at $4.5 \mathrm{~m} \mathrm{~s}^{-1}$ (as described in the Materials and methods section, sonomicrometry and EMG recordings were made in the lateral head of the gastrocnemius). Although considerable length change is observed during the swing phase of the stride, length changes are much smaller during stance (plantaris, $<1 \mathrm{~mm}$; lateral gastrocnemius, $<2 \mathrm{~mm}$ ), particularly when the muscles are generating high levels of force. Much of the shortening of the lateral gastrocnemius occurs early in stance, when the muscle is generating less than $33 \%$ of maximum force. (B) Cycle 2 in A shown on an expanded time scale. Neural activation of the muscles precedes force development, continuing through approximately two-thirds of the period of force generation during stance (see Fig. 4 for a summary of the timing of EMG activity relative to force development).

\section{Timing of muscle EMG, force development and limb contact time}

Neural activation of the muscles, as determined from the onset of the EMG, preceded the onset of force development by $49 \pm 5 \mathrm{~ms}$ in the plantaris and $40 \pm 9 \mathrm{~ms}$ in the lateral gastrocnemius (Table 3), with excitation continuing for $67 \pm 12 \%$ (PL) and $71 \pm 12 \%$ (LG) of the period of force development. Using the time of force onset as the start of the cycle phase (Fig. 4), activation of the plantaris and lateral gastrocnemius averaged, respectively, a $17 \%$ and $14 \%$ phase advance relative to force development. Although there was a tendency for EMG duration to decrease (Table 3; PL duration, $P=0.05$; LG duration, $P=0.10$ ) and for force duration to decrease (see Fig. 5) with increased hopping speed, the general pattern shown in Fig. 4 was maintained over the observed range of hopping speeds. In general, force development within the gastrocnemius preceded force development within the plantaris by $18 \pm 8 \mathrm{~ms}$ (pooled for all animals and speeds, $N=140$ ).
In a previous study (Biewener and Baudinette, 1995), three of the same wallabies increased their hopping speed by increasing their stride length by $89 \%(P<0.001)$ but also by increasing their stride frequency by $11 \%(P<0.01)$. Because of the modest increase in stride frequency, the time of limb contact estimated by the duration of gastrocnemius force generation $T_{\mathrm{c}}{ }^{*}(P<0.001)$ and hindlimb duty factor $(P<0.01$; data for wallabies 1,2 and 3 , excluding the smaller wallaby 4$)$ decreased gradually with increasing hopping speed (Fig. 5). Consequently, increases in muscle force generation necessary to achieve greater stride lengths occurred over shorter periods, significantly increasing the rates of muscle activation and force development during ground contact at faster speeds.

\section{Force-length behavior of hindlimb muscles}

Graphs of in vivo force versus length show that the plantaris fibers exhibited stiff stretch-shorten contractile behavior, with less than $2 \%$ changes in fiber length while developing force 
Table 2. Muscle fiber length changes, force and work for Macropus eugenii hopping at different speeds

\begin{tabular}{|c|c|c|c|c|c|c|c|c|c|c|}
\hline \multirow{2}{*}{$\begin{array}{l}\text { Muscle } \\
\text { Individual }\end{array}$} & \multirow[b]{2}{*}{$N$} & \multirow{2}{*}{$\begin{array}{l}\text { Speed } \\
\left(\mathrm{m} \mathrm{s}^{-1}\right)\end{array}$} & \multirow{2}{*}{$\begin{array}{l}\Delta L_{\mathrm{f}}(\mathrm{mm}) \\
(\mathrm{on} \rightarrow \text { peak })\end{array}$} & \multirow{2}{*}{$\begin{array}{c}\Delta L_{\mathrm{f}}(\mathrm{mm}) \\
(\text { peak } \rightarrow \text { off })\end{array}$} & \multicolumn{2}{|c|}{ Net $\Delta L_{\mathrm{f}}$} & \multirow{2}{*}{$\begin{array}{c}\text { Force } \\
(\mathrm{N})\end{array}$} & \multicolumn{2}{|c|}{ Muscle work (J) } & \multirow{2}{*}{$\begin{array}{c}E_{\text {elas }} \\
(\mathrm{J})\end{array}$} \\
\hline & & & & & $(\mathrm{mm})$ & $(\%)$ & & Shortening & Net & \\
\hline \multicolumn{11}{|l|}{ Plantaris } \\
\hline \multirow[t]{3}{*}{1} & 16 & 3.5 & $0.41 \pm 0.09$ & $-0.49 \pm 0.10$ & $-0.08 \pm 0.11$ & -0.5 & $179 \pm 10$ & $0.04 \pm 0.01$ & $0.02 \pm 0.01$ & 0.45 \\
\hline & 16 & 4.5 & $0.52 \pm 0.13$ & $-0.54 \pm 0.15$ & $-0.02 \pm 0.16$ & -0.1 & $201 \pm 9$ & $0.05 \pm 0.01$ & $0.01 \pm 0.02$ & 0.67 \\
\hline & 16 & 5.5 & $0.47 \pm 0.16$ & $-0.43 \pm 0.19$ & $0.04 \pm 0.22$ & 0.1 & $228 \pm 16$ & $0.05 \pm 0.02$ & $-0.01 \pm 0.03$ & 1.06 \\
\hline \multirow[t]{3}{*}{2} & 14 & 3.5 & $-0.05 \pm 0.24$ & $0.40 \pm 0.60$ & $0.35 \pm 0.55$ & 2.3 & $202 \pm 8$ & $0.02 \pm 0.01$ & $-0.02 \pm 0.01$ & 0.65 \\
\hline & 16 & 4.5 & $0.04 \pm 0.14$ & $-0.13 \pm 0.13$ & $-0.09 \pm 0.18$ & -0.6 & $219 \pm 6$ & $0.03 \pm 0.02$ & $-0.03 \pm 0.01$ & 0.80 \\
\hline & 16 & 5.0 & $-0.07 \pm 0.09$ & $-0.33 \pm 0.16$ & $-0.40 \pm 0.21$ & -2.6 & $251 \pm 20$ & $0.05 \pm 0.02$ & $0.03 \pm 0.02$ & 0.96 \\
\hline \multirow[t]{5}{*}{3} & 14 & 3.0 & $0.36 \pm 0.17$ & $-0.47 \pm 0.07$ & $-0.11 \pm 0.18$ & -0.6 & $231 \pm 20$ & $0.04 \pm 0.01$ & $0.01 \pm 0.03$ & 0.59 \\
\hline & 15 & 3.5 & $0.41 \pm 0.11$ & $-0.31 \pm 0.19$ & $0.11 \pm 0.22$ & 0.6 & $251 \pm 15$ & $0.03 \pm 0.01$ & $-0.03 \pm 0.02$ & 0.61 \\
\hline & 18 & 4.5 & $0.52 \pm 0.17$ & $-0.40 \pm 0.12$ & $0.12 \pm 0.18$ & 0.7 & $273 \pm 13$ & $0.05 \pm 0.02$ & $-0.04 \pm 0.02$ & 1.50 \\
\hline & 17 & 5.5 & $0.43 \pm 0.22$ & $-0.49 \pm 0.25$ & $-0.06 \pm 0.29$ & -0.3 & $342 \pm 34$ & $0.08 \pm 0.06$ & $-0.05 \pm 0.07$ & 1.66 \\
\hline & 16 & 6.0 & $0.49 \pm 0.23$ & $-0.43 \pm 0.24$ & $0.06 \pm 0.25$ & 0.3 & $371 \pm 37$ & $0.09 \pm 0.05$ & $-0.03 \pm 0.06$ & 1.74 \\
\hline \multicolumn{11}{|c|}{ Gastrocnemius } \\
\hline \multirow[t]{3}{*}{2} & 14 & 3.5 & $0.68 \pm 0.48$ & $0.13 \pm 0.46$ & $0.81 \pm 0.53$ & 4.0 & $276 \pm 15$ & $0.04 \pm 0.01$ & $-0.34 \pm 0.07$ & 0.70 \\
\hline & 16 & 4.5 & $0.67 \pm 0.50$ & $0.11 \pm 0.49$ & $0.78 \pm 0.30$ & 3.9 & $280 \pm 20$ & $0.03 \pm 0.03$ & $-0.26 \pm 0.06$ & 0.85 \\
\hline & 16 & 5.0 & $0.45 \pm 0.40$ & $0.53 \pm 0.71$ & $0.98 \pm 0.46$ & 4.8 & $303 \pm 32$ & $0.06 \pm 0.02$ & $-0.38 \pm 0.07$ & 1.04 \\
\hline \multirow[t]{5}{*}{3} & 14 & 3.0 & $-1.44 \pm 1.11$ & $-0.75 \pm 0.69$ & $-2.19 \pm 1.13$ & -12.2 & $180 \pm 21$ & $0.13 \pm 0.04$ & $0.09 \pm 0.07$ & 0.62 \\
\hline & 15 & 3.5 & $-1.25 \pm 0.62$ & $-0.71 \pm 0.49$ & $-1.96 \pm 0.78$ & -10.9 & $211 \pm 34$ & $0.09 \pm 0.03$ & $-0.01 \pm 0.06$ & 0.78 \\
\hline & 18 & 4.5 & $-1.19 \pm 0.32$ & $-0.53 \pm 0.32$ & $-1.72 \pm 0.43$ & -9.6 & $220 \pm 14$ & $0.11 \pm 0.06$ & $0.08 \pm 0.06$ & 0.88 \\
\hline & 17 & 5.5 & $-1.42 \pm 0.69$ & $-0.25 \pm 0.87$ & $-1.67 \pm 0.85$ & -9.3 & $226 \pm 24$ & $0.14 \pm 0.06$ & $0.13 \pm 0.07$ & 1.10 \\
\hline & 16 & 6.0 & $-1.53 \pm 0.77$ & $-0.29 \pm 0.53$ & $-1.82 \pm 0.91$ & -10.1 & $235 \pm 31$ & $0.16 \pm 0.07$ & $0.15 \pm 0.08$ & 1.24 \\
\hline \multirow[t]{3}{*}{4} & 14 & 3.1 & $1.81 \pm 0.39$ & $-0.22 \pm 0.38$ & $1.59 \pm 0.39$ & 9.7 & $169 \pm 27$ & $0.02 \pm 0.02$ & $-0.31 \pm 0.08$ & 0.56 \\
\hline & 15 & 4.2 & $1.69 \pm 0.33$ & $-0.24 \pm 0.28$ & $1.45 \pm 0.31$ & 8.8 & $195 \pm 18$ & $0.02 \pm 0.01$ & $-0.44 \pm 0.09$ & 0.77 \\
\hline & 14 & 5.1 & $1.85 \pm 0.36$ & $-0.39 \pm 0.63$ & $1.49 \pm 0.55$ & 9.1 & $203 \pm 16$ & $0.04 \pm 0.01$ & $-0.42 \pm 0.07$ & 1.02 \\
\hline \multicolumn{11}{|c|}{$\begin{array}{l}\text { Work calculated for the gastrocnemius muscle was determined on the basis of fiber length changes }\left(\Delta L_{\mathrm{f}}\right) \text { recorded in the lateral gastrocnemius and the total force generated by the } \\
\text { medial and lateral gastrocnemius muscles combined. This assumes that length changes of the medial gastrocnemius are the same as those of the lateral gastrocnemius. }\end{array}$} \\
\hline \multirow{2}{*}{\multicolumn{11}{|c|}{$\begin{array}{l}\text { Values of } E_{\text {elas }} \text { (tendon elastic strain energy) are based on measurements presented in an earlier paper (Biewener et al. 1995). These values have been corrected (on average a } 34 \% \\
\text { decrease) for errors in the previously reported values of gastrocnemius } E_{\text {elas }} \text { due to the use of mistaken values of tendon volume. }\end{array}$}} \\
\hline & & & & & & & & & & \\
\hline \multirow{2}{*}{\multicolumn{11}{|c|}{$\begin{array}{l}\Delta L_{\mathrm{f}} \text {, change in whole muscle fiber length; on } \rightarrow \text { peak, from onset of force increase to peak force; peak } \rightarrow \text { off, from peak force to when force returned to baseline. } \\
\text { Measurements of } \Delta L_{\mathrm{f}} \text { for the gastrocnemius muscle were made in the lateral head and were used to determine work for the lateral and medial heads combined. }\end{array}$}} \\
\hline Values are & & & & & & & & & & \\
\hline
\end{tabular}


1688 A. A. Biewener, D. D. Konieczynski and R. V. Baudinette

Table 3. Timing of EMG and force development in Macropus eugenii hopping at different speeds

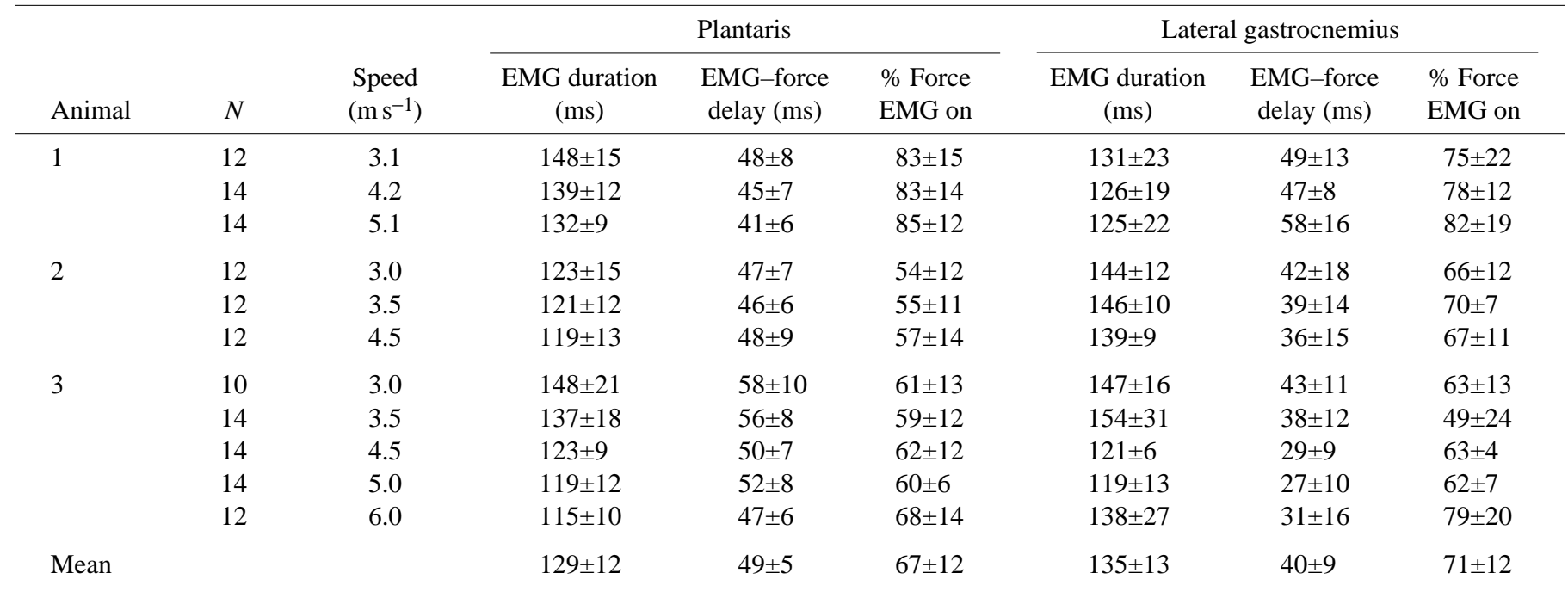

Values are means \pm S.D.

EMG-force delay is the time difference between EMG onset and the start of force development; \% Force EMG on is the percentage of the period of active force development during which EMG activity occurred.

during the stance phase of the stride in three animals (Figs 6A, 7A). Some initial shortening by the fibers occurred early at very low force levels, but this was rapidly reversed, with a stiff rise in force as the fibers were stretched by less than $2 \%$ of their length followed by a subsequent shortening phase of fairly uniform stiffness. These small length changes suggest that the majority of fiber length change occurred by elastic extension of myosin cross-bridges attached to the actin filaments. If this was the case, the muscle's fibers stored and recovered as much as $0.091 \mathrm{~J}$ at $6.0 \mathrm{~m} \mathrm{~s}^{-1}$ on the basis of measured length changes $(0.49 \mathrm{~mm})$ and forces $(371 \mathrm{~N})$ obtained for wallaby 3 assuming linear elasticity (Table 2). This represents approximately $5 \%$ of the strain energy stored and recovered by the muscle's tendon.

The force-length behavior of the lateral gastrocnemius (Figs 6B, 7B), although less consistent among animals, also exhibited force development with generally small $(<6 \%)$ changes in fiber length relative to rest length. Whereas contractions of the lateral gastrocnemius (LG) muscles of wallabies 4 and 2 described narrow (but much wider than for the plantaris) clockwise negative work loops, the LG of wallaby 3 developed force isometrically $\left(\Delta L_{\mathrm{f}}<2 \% L_{\mathrm{f}}\right)$ at higher levels of force during mid-stance. The majority of LG fiber shortening in wallabies 2 and 3 occurred early in stance at low levels of force. In wallaby 4, little, if any, shortening occurred before the muscle developed force isometrically. Fiber lengthening occurred after the initial shortening or isometric phase in all three animals close to mid-support and was greatest in wallaby 4 . The greater length changes observed in the lateral gastrocnemius compared with the plantaris suggest that elastic energy stored within the cross-bridges during stretching was probably lost as the cross-bridges detached and re-attached during the contraction cycle (note that this may not have been the case for wallaby 3 ).

Force-length changes were consistent for individual muscles over a series of successive strides at a particular speed (this is shown in Fig. 7 for wallaby 3), as well as over a range of of steady hopping speeds (Figs 8; Table 2). Both the stretch-shorten length changes of the plantaris (active stiffness $580 \pm 114 \mathrm{~N} \mathrm{~mm}^{-1}$ ) and the nearly isometric behavior of the lateral gastrocnemius in wallaby 3 (during mid-stance and late stance), for example, were uniformly observed at different
Fig. 4. Summary diagram showing mean onset and offset times and phase relationships of muscle activation (EMG timing) relative to force development over an entire hopping cycle. Data represent the mean \pm S.D. of values pooled for all animals over all speeds $(N=123)$. Although slight decreases in EMG duration (Table 3) and force duration $\left(T_{\mathrm{c}}{ }^{*}\right.$, Fig. 5) occur with increased hopping speed, the general timing and phase relationships of the patterns shown hold for a range of hopping speeds.

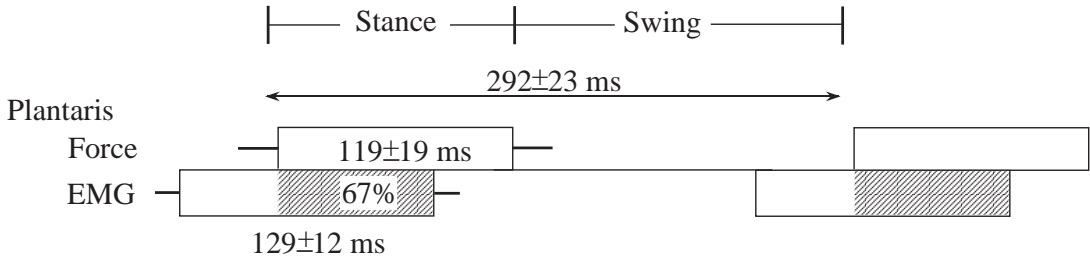

Gastrocnemius

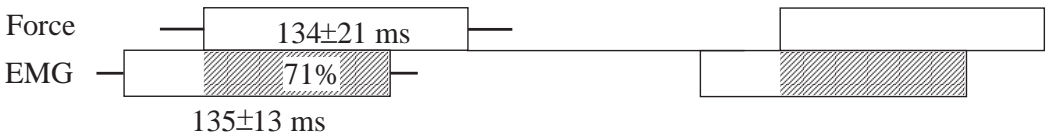




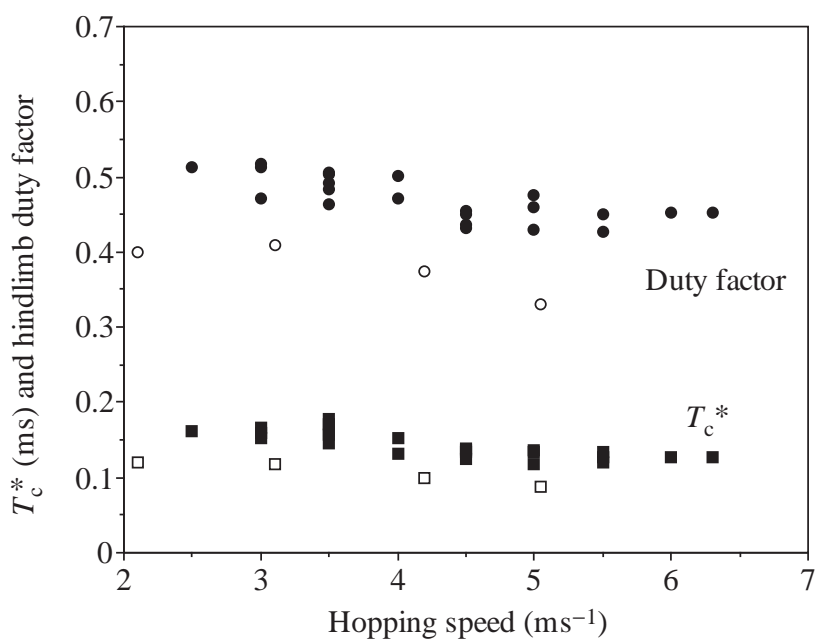

Fig. 5. Limb contact time $\left(T_{\mathrm{c}}{ }^{*}\right.$, squares) estimated by the duration of force exerted by the gastrocnemius muscle, and hindlimb duty factor (circles) versus hopping speed $(v) . T_{\mathrm{c}}{ }^{*}$ (least squares regression: $T_{\mathrm{c}}{ }^{*}=-0.014 v+0.201 ; r^{2}=0.66, P<0.001$ for filled points) and hindlimb duty factor $\left(T_{\mathrm{c}}{ }^{*}=-0.021 v+0.576 ; r^{2}=0.55, P<0.01\right.$ for filled symbols $)$ decrease modestly, but significantly, with increased speed, corresponding to a slight (11\%), but significant, increase in stride frequency (Biewener and Baudinette, 1995) over this speed range (filled symbols are for wallabies 1,2 and 3; open symbols are for the smaller wallaby 4). hopping speeds (Fig. 8). LG fiber shortening at relatively low force levels early in stance was also a consistent feature of force development in this muscle at speeds greater than $2.5 \mathrm{~m} \mathrm{~s}^{-1}$ (Fig. 8).

\section{Fiber length changes, muscle work and tendon strain energy} recovery versus speed

Changes in muscle fiber length during limb support varied little over the measured range of hopping speeds, showing little evidence of an increase in fiber stretch with increased force development at faster speeds (Table 2). When stretch of the muscle fibers occurred, it was considerably less than the series elastic extension calculated for the muscles' tendons: muscle fiber stretch averaged $7 \pm 4 \%$ (range 5-9\%) of tendon stretch in the plantaris and $34 \pm 12 \%$ (range 10-49\%) of tendon stretch in the lateral gastrocnemius for all speeds. The generally small length changes in the plantaris and lateral gastrocnemius muscles of all animals (Table 2) and, in particular, the absence of fiber stretch during the decline in force, provide strong evidence that strain energy recovered from the tendons is effectively returned to the whole animal at all hopping speeds. The small length changes of the muscle fibers compared with the stretch of their tendons also meant that the amount of shortening work performed by the muscles was small relative to the amount of strain energy recovered by their tendons to do work (Table 2). Tendon strain energy averaged 21 times
Fig. 6. In vivo force-length changes obtained for (A) the plantaris and (B) the lateral gastrocnemius muscles recorded over one full cycle (stance and swing) during steady-speed hopping of four wallabies; wallaby 1 at $4.2 \mathrm{~m} \mathrm{~s}^{-1}$ and wallabies 2-4 at $4.5 \mathrm{~m} \mathrm{~s}^{-1}$. Reliable recordings of length change were obtained from three of the four animals for each muscle. In the case of wallaby 1 , reliable recordings were only obtained from the plantaris; whereas only the lateral gastrocnemius yielded reliable results in wallaby 4 . In all animals studied, the plantaris undergoes stiff stretch-shorten length changes during force generation, with the majority of length change occurring near zero force (i.e. during the swing phase of the limb). The lateral gastrocnemius exhibits either negative (clockwise, wallaby 2 and 4) work loops or generally isometric behavior (wallaby 3). Black bars denote a $6 \%$ change in resting fiber length. Arrows indicate the direction of length change of the work loops. Although the negative work loops of the lateral
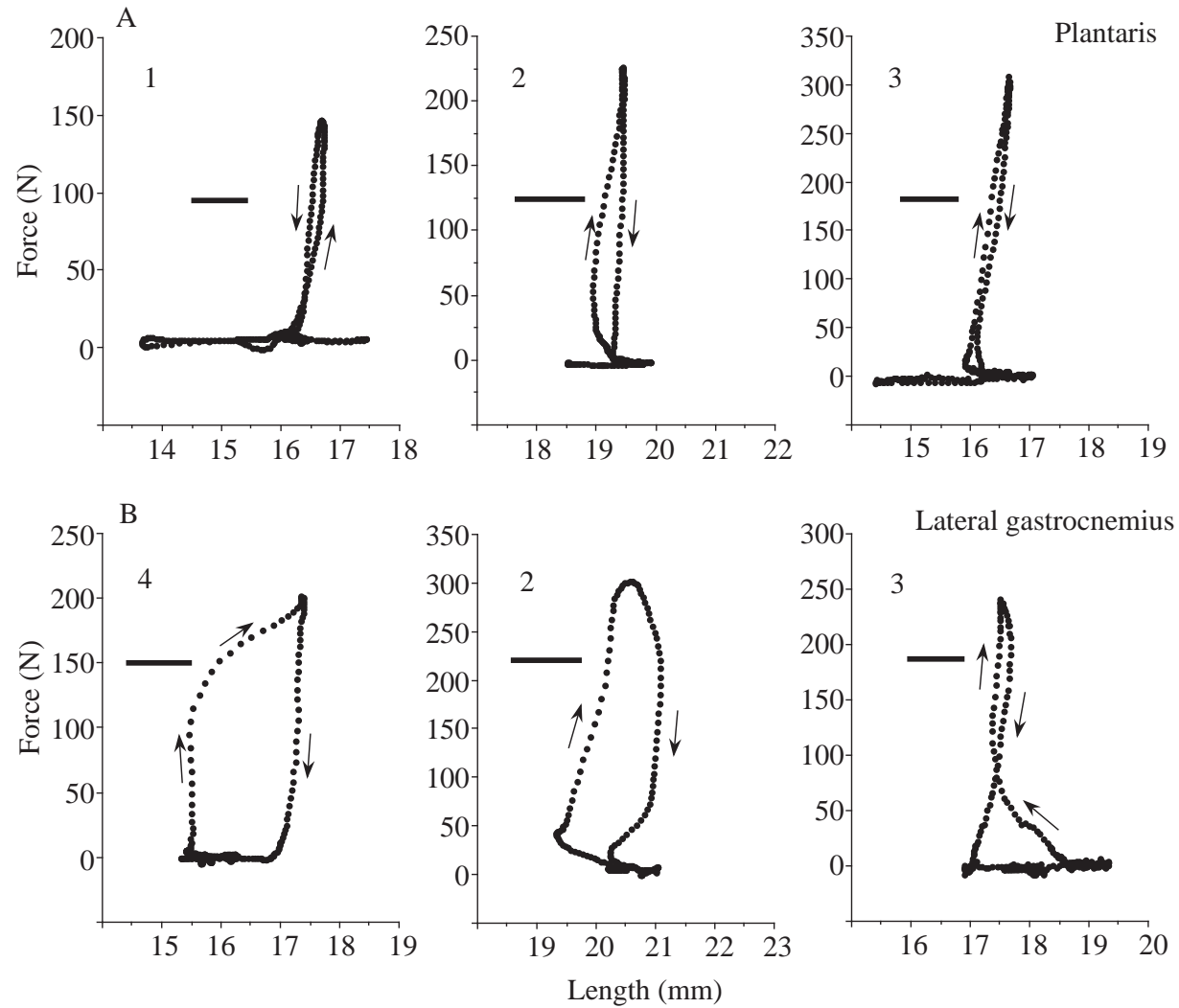

gastrocnemius of wallabies 2 and 4 are broad relative to the length change of the plantaris, they represent a change in muscle fiber length over the whole cycle of less than a total of $12 \%$. 

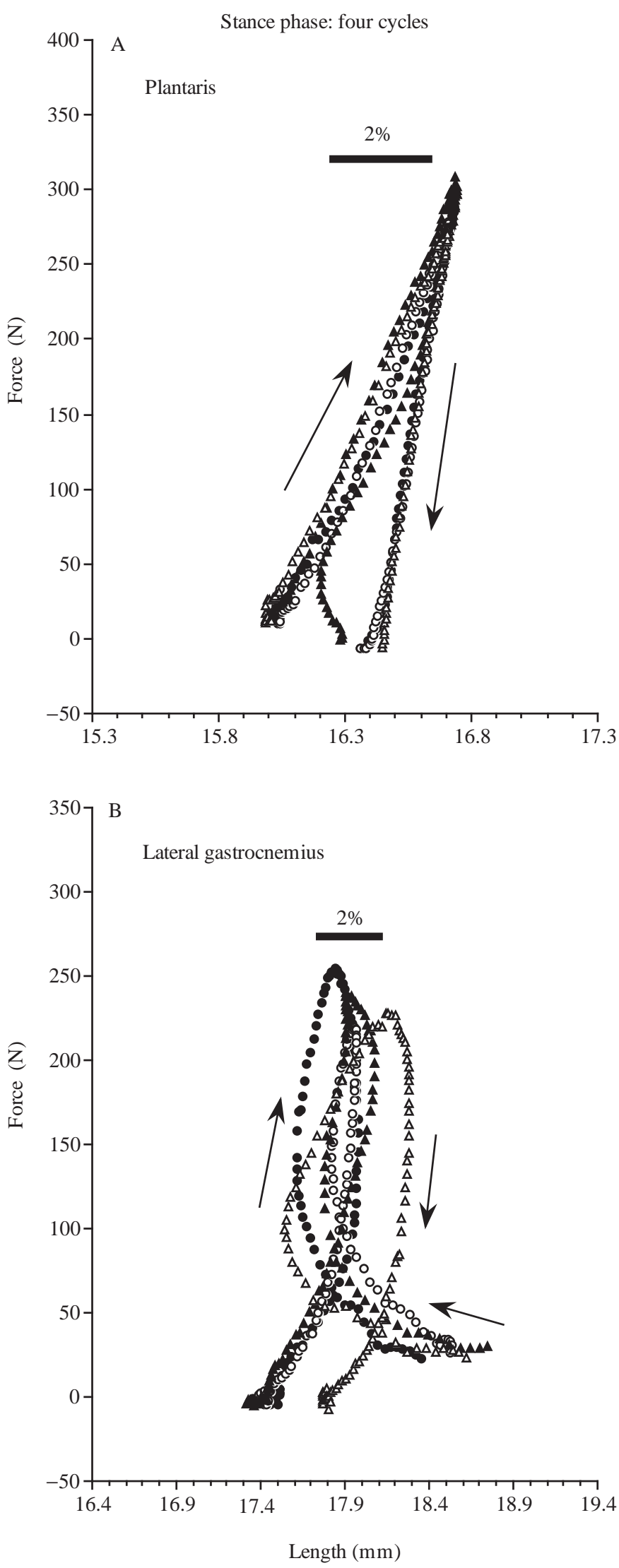

muscle shortening work in the plantaris and 19 times muscle shortening work in the gastrocnemius over the range of
Fig. 7. Force-length changes of the plantaris (A) and lateral gastrocnemius (B) for four successive stance phase cycles of wallaby 3 at $4.5 \mathrm{~m} \mathrm{~s}^{-1}$ (in order: filled circles, open circles, filled triangles, open triangles). Note the expanded length scale compared with Fig. 6. Percentage length changes of both muscles are less than $4 \%$ of resting length for forces exceeding $33 \%$ of maximum force. Arrows indicate the direction of muscle length change. Bars indicate $2 \%$ of resting fiber length.

recorded speeds [note that the values for gastrocnemius $E_{\text {elas }}$ have been corrected, being on average $34 \%$ less, from our previously reported values (Biewener and Baudinette, 1995), because of an error in the values of tendon volume used in our earlier calculation of gastrocnemius $E_{\text {elas; }}$; the implications of this are discussed below]. Whereas recovery of elastic strain energy $\left(E_{\text {elas}}\right.$, in $\left.\mathrm{J}\right)$ in the hindlimb tendons increased significantly with hopping speed $\left(E_{\text {elas }}=0.51 v-0.34\right.$, where $v$ is speed in $\mathrm{m} \mathrm{s}^{-1} ; P<0.001 ; r^{2}=0.94$ ), muscle shortening work remained low and increased only slightly with hopping speed (Fig. 9). In most cases, the shortening work done by the two muscles was offset by a phase of (negative) lengthening work, which also contributed to the small amount of net work that they performed.

\section{Discussion}

The force-length behavior of the plantaris and lateral gastrocnemius muscles of tammar wallabies recorded in vivo confirms the ability of these muscles to generate force with minimal length change during steady-speed hopping, enabling their tendons to store and recover increasing amounts of elastic strain energy at faster speeds. Fiber length change was generally less than $2 \%$ in the plantaris and less than $6 \%$ in the lateral gastrocnemius (in all animals at forces above $33 \%$ of maximum force) over a range of hopping speeds from 2.5 to $6.0 \mathrm{~m} \mathrm{~s}^{-1}$. In addition to the strain energy stored and recovered in the tendons, it seems likely that strain energy is recovered from the fibers of the plantaris muscle as well. The short-range extension of these fibers is consistent with the view that their length change results from the elastic extension and recoil of myosin cross-bridges attached to actin filaments during force generation, enabling elastic energy savings by the muscle (Alexander and Bennet-Clark, 1977; Rack and Westbury, 1974). On the basis of our measurements of force and length, we estimate that this could be as high as $0.091 \mathrm{~J}$ at $6 \mathrm{~m} \mathrm{~s}^{-1}$, although this represents only approximately $5 \%$ of the energy stored by the muscle's tendon (Table 2). For greater extensions, such as those observed in the lateral gastrocnemius, it is likely that elastic energy stored in the cross-bridges is lost because the cross-bridges would need to detach and re-attach in order to exert force over the longer length changes (Flitney and Hirst, 1978; Morgan et al. 1978; Rack and Westbury, 1974).

Although in situ measurements of the medial gastrocnemius of the closely related wallaby species Thylogale billardierii suggested that muscle stiffness is too low to allow increased 
Fig. 8. Force-length graphs from the plantaris and lateral gastrocnemius muscles of wallaby 3 at five different hopping speeds. Force-length changes and muscle stiffness $\left(580 \pm 114 \mathrm{~N} \mathrm{~mm}^{-1}\right)$ of the plantaris are maintained uniformly at all hopping speeds. Similar patterns of force-length behavior are also observed in the lateral gastrocnemius (LG) at different speeds. The majority of LG fiber shortening occurs early in limb support as force begins to develop, at all speeds greater than $2.5 \mathrm{~m} \mathrm{~s}^{-1}$. Thereafter, the rise and fall in force are largely isometric ( $<4 \%$ length change) during mid-stance and late stance. Both muscles also operate over the same general range of fiber length at different speeds (resting length shown below each graph (in $\mathrm{mm}$ ), with the scale bar denoting $1 \mathrm{~mm}$ ).

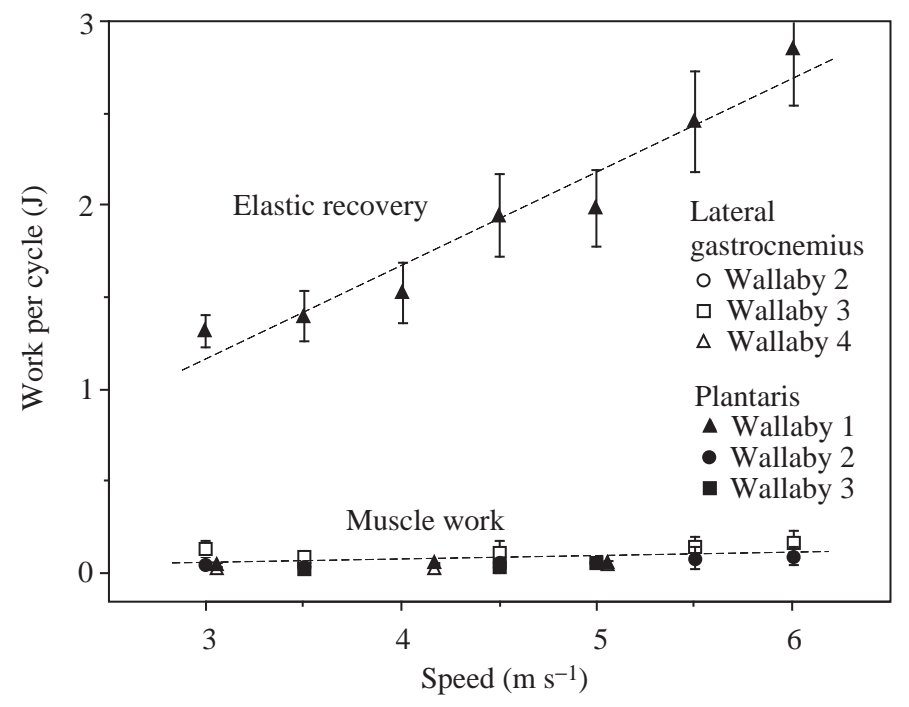

Fig. 9. Comparison of the effective work recovered by elastic strain energy $\left(E_{\text {elas }}\right)$ in the plantaris and gastrocnemius tendons versus shortening work performed by the same two muscles as a function of hopping speed. Only those values for which data were available for both muscles and tendons at a given speed are plotted. Consequently, not all of the data given in Table 2 are represented here. Error bars denote \pm 1 S.D. of the mean values pooled among animals at each speed $(N>28)$. Whereas tendon strain energy recovery increases with increasing hopping speed $\left(E_{\text {elas }}=0.512 v-0.338\right.$, where $v$ is speed in $\mathrm{m} \mathrm{s}^{-1} ; P<0.001 ; r^{2}=0.94$, based on least-squares regression), muscle work remains low and increases only modestly with speed $\left(W_{\text {short }}=0.019 v-0.018 ; \quad P=0.042, \quad r^{2}=0.19\right)$. Tendon strain energy recovery averaged 20 -fold greater than muscle shortening work over this speed range.
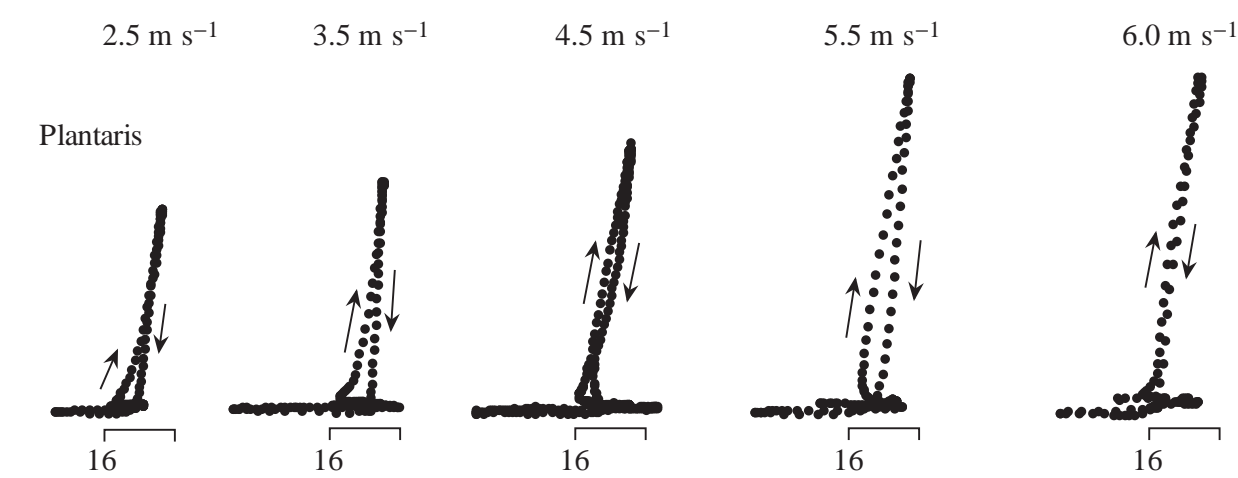

Lateral gastrocnemius
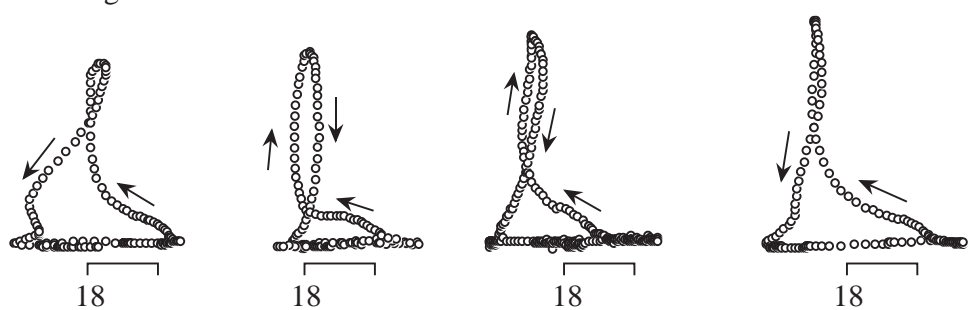

18

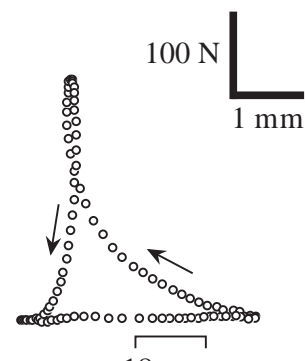

18

strain energy recovery within the tendon at faster hopping speeds (Griffiths, 1989), our measurements show that, for the plantaris and lateral gastrocnemius muscles of tammar wallabies, this is not the case. Griffiths (1989) argued that any increase in tendon strain energy due to increased muscle force development at faster hopping speeds would result in greater stretch of the muscle's fibers (beyond their short-range stiffness), causing the fibers to absorb and dissipate any additional energy stored in the tendon. Consequently, Griffiths (1989) concluded that, although tendon strain energy is recovered to do work, an increase in tendon elastic energy savings could not explain the levelling off in metabolic cost at faster hopping speeds. In our present experiments, however, stretch of the muscles' fibers was never observed as force decreased from its peak during the second half of limb support (Figs 6,8). This is the period when elastic strain energy stored in the tendon (and muscle) would be recovered and returned to the animal to help power its hopping. Under in vivo conditions, therefore, the fibers of these two muscles are capable of maintaining sufficient stiffness during tendon recoil over the range of speeds that we observed to prevent the absorption and dissipation of strain energy stored in their tendons.

Because we were unable to measure length changes of the medial gastrocnemius muscle via sonomicrometry in these experiments, we cannot rule out the possibility that the tammar medial gastrocnemius, like that of thylogale wallabies, may not maintain the same level of stiffness that we measured in the lateral gastrocnemius. If the medial gastrocnemius were to undergo considerably greater stretch as the speed of hopping increased, much of the strain energy stored within the Achilles tendon might be dissipated by its fibers, rather than being 


\section{A. A. Biewener, D. D. Konieczynski And R. V. BAudinetTe}

usefully recovered, as suggested by the behavior of the lateral gastrocnemius. However, this seems unlikely for three reasons. First, our results for tendon strain energy storage within these two muscle-tendon units, together with the flexor digitorum longus and its tendon (Biewener and Baudinette, 1995), are consistent with the metabolic savings observed for tammar wallabies (Baudinette et al. 1992). Accounting for our earlier error in the values of tendon volume used to calculate gastrocnemius $E_{\text {elas }}$ (Biewener and Baudinette, 1995), the $34 \%$ lower values of gastrocnemius $E_{\text {elas }}$ reported here mean that the net contribution of the gastrocnemius to total elastic savings is $41 \%$, compared with $47 \%$ by the plantaris tendon and $12 \%$ by the flexor digitorum longus tendon (our previous estimates had been $52 \%$ for the gastrocnemius, $38 \%$ for the plantaris and $10 \%$ for the flexor digitorum longus). These (corrected) relative contributions of tendon elastic savings agree much better with those estimated by Ker et al. (1986) for a Bennett's wallaby (Macropus rufogriseus). Overall, this means that total energy savings by these three tendons in the tammar wallaby are $88 \%$ of the value we reported previously (Biewener and Baudinette, 1995). Consequently, our corrected measurements suggest that metabolic savings by elastic storage within these three tendons (assuming a muscle efficiency of 0.25 ) can be as high as $45 \%$ at $6.0 \mathrm{~m} \mathrm{~s}^{-1}$ and are likely to be greater at higher speeds. Second, its seems unlikely that two muscles which transmit force jointly to the same tendon would differ significantly in their active stiffness and undergo substantially different changes of length under conditions of agonist co-activation. Third, the dynamic contractile properties of muscle under in vivo conditions of neural activation are likely to differ from those measured under quasi-static in situ conditions. Nevertheless, corresponding in vivo fiber length measurements of the medial gastrocnemius are needed to confirm these points.

Griffiths (1989) reported whole-muscle force-length curves similar to those that we measured for the plantaris fibers, in which force development exhibited active lengthening followed by active shortening, while maintaining fairly uniform stiffness. Griffiths (1989) estimated that the fibers of the thylogale wallaby medial gastrocnemius initially shortened as force was first developed, but could not verify this because his measurements were for the whole muscle and were assessed indirectly from limb kinematics (subtracting calculated series-elastic tendon length changes). In a subsequent study of the medial gastrocnemius of walking and trotting cats Felis domesticus, Griffiths (1991) demonstrated muscle fiber shortening during whole muscle-tendon stretch using sonomicrometry. Our recordings from plantaris fibers also showed a small degree of initial shortening at very low levels of force, but this was seen more clearly in the fibers of the tammar wallaby lateral gastrocnemius. Fiber shortening during stretch of the whole muscle-tendon unit has also been observed using sonomicrometry in the medial gastrocnemius of running turkeys Meleagris galapavo (Roberts et al. 1997). This is explained by the low stiffness of the tendon at low forces (Bennett et al. 1986; Ker, 1981; Shadwick, 1990), which allows the muscle's fibers to shorten initially, so that stretch of the whole muscle and tendon is taken up by the tendon and connective tissue elements within the muscle. As force develops further, the tendon's stiffness increases rapidly, causing the fibers of the muscle to remain isometric (as observed here in the tammar wallaby lateral gastrocnemius) or to be stretched (as observed here in the plantaris). Although Roberts et al. (1997) do not report muscle force-length curves, their recordings of fiber length change and force of the medial gastrocnemius of turkeys running on a level surface clearly indicate an initial period of fiber shortening followed by a period of rapid isometric force development. Consequently, it is likely that the force-length curves of the medial gastrocnemius of running turkeys are similar to those obtained in the present study for the lateral gastrocnemius of wallabies 2 and 3.

Consistent with the primary role of these muscles to generate force, rather than to perform work, muscle fiber length changes in the tammar wallaby were considerably smaller than those calculated for their tendons (13-fold less in the plantaris and fourfold less in the lateral gastrocnemius, based on a tendon stress of $35 \mathrm{MPa}$ at $6.0 \mathrm{~m} \mathrm{~s}^{-1}$; Biewener and Baudinette, 1995). As a result, muscle shortening work was considerably less than tendon strain energy storage at all measured hopping speeds. The function of muscles to generate force economically by means of isometric contractile behavior, rather than to perform work, was originally emphasized by Roberts et al. (1997) in their study of the medial gastrocnemius in running turkeys. Using methods similar to those employed here, Roberts et al. (1997) found that the fibers of the medial gastrocnemius shortened by less than $7 \%$ of fiber length and that tendon energy storage and recovery accounted for more than $60 \%$ of the work of the muscle-tendon unit during level running. In comparison, tendon strain energy recovery in the tammar wallaby represented $92-97 \%$ of the shortening work performed by the plantaris and gastrocnemius muscle-tendon units at speeds greater than $3.0 \mathrm{~m} \mathrm{~s}^{-1}$ (Fig. 9).

By not shortening to perform work, fewer fibers must be recruited to generate a given force, presumably lowering the amount of ATP consumed by the muscle. This appears to be a key functional feature of wallaby leg muscles during hopping, which was also noted by Griffiths (1989) in his study of the thylogale wallaby medial gastrocnemius. The stiff stretch-shortening behavior of the plantaris muscle, in fact, suggests even greater economy of force generation. Because active stretch of a muscle can enhance force development by as much as 1.8 times its isometric force (Cavagna and Citterio, 1974; Flitney and Hirst, 1978; Harry et al. 1990), the economy of muscle fiber recruitment and, hence, energy savings in the form of ATP consumption within the fibers of the tammar wallaby plantaris are likely to be greater than those of an isometrically contracting muscle. Differences in ATP consumption for these two conditions, however, are also likely to depend on the degree to which the rate of cross-bridge cycling differs under isometric versus lengthening conditions of force development, which at present remains unclear. 
Roberts et al. (1997) interpret their findings of isometric force generation within the turkey medial gastrocnemius as evidence in support of the view that the metabolic cost of locomotion is largely determined by (1) the amount of energy consumed by a muscle to generate force per unit time (rather than muscle work) and (2) the rate of force development (Heglund et al. 1982; Heglund and Taylor, 1988; Kram and Taylor, 1990). According to this view, the increase in metabolic cost with speed is due to increases in force generation and stride frequency at faster speeds. Similarly, the greater mass-specific metabolic cost of smaller species appears to be explained by the increased cost of generating force at higher rates of force development associated with their greater stride frequencies at comparable points of the gait (Heglund and Taylor, 1988). Although the lateral gastrocnemius and plantaris muscles of tammar wallabies also exhibit isometric or stiff stretch-shorten contractile behavior, consistent with their hopping gait, red kangaroos Macropus rufus (Dawson and Taylor, 1973), tammar wallabies (Baudinette et al. 1992) and possibly other moderate-sized to large macropodids do not fit the general locomotor pattern of energy expenditure versus speed. This has been interpreted by several workers (Alexander and Vernon, 1975; Bennett and Taylor, 1995; Biewener and Baudinette, 1995; Cavagna et al. 1977; Morgan et al. 1978) as being based on their ability to save considerable metabolic energy by tendon elastic savings.

Significant elastic savings, however, are also believed to occur in the tendons and ligaments of other large mammals (Alexander et al. 1982; Biewener, 1998; Cavagna et al. 1977; Dimery and Alexander, 1985; Dimery et al. 1986a,b), including humans (Ker et al. 1987). Nevertheless, it is only in moderate-sized to large macropodids that these savings appear sufficient to alter the linear relationship between metabolic energy expenditure and speed that is otherwise generally observed for the locomotion of terrestrial species (Taylor et al. 1982). The absence of a similar effect of elastic energy savings on whole-animal energetics in the locomotion of animals, such as ungulates, which have highly specialized muscles and tendons favoring elastic savings and economical muscle force generation (i.e. very short muscle fibers attached to long tendons), is therefore difficult to explain. It remains unclear why such savings in the leg tendons of wallabies and kangaroos, which are less specialized than those of ungulates (Ker et al. 1986), enable a significant reduction in the metabolic cost of movement at faster speeds that is not observed in running ungulates and other terrestrial mammals and birds.

Consequently, while our measurements lend strong support to the central role of elastic energy saving in the hindlimb tendons as the means by which wallabies and kangaroos increase their speed with little or no increase in energy expenditure, their ability to do so still seems remarkable given that ungulates do not show a similar pattern. In addition, because wallaby muscles must generate greater forces and at faster rates as hopping speed increases (decrease in $T_{\mathrm{c}}{ }^{*} ;$ Fig. 5), the arguments outlined above suggest that increases in elastic energy savings require increased energy utilization within the muscle. Not only does muscle force increase with hopping speed, but net muscle work (of the whole animal) will also presumably increase to achieve the increase in stride length that is necessary for increasing speed in these animals. Because our measurements show that the plantaris and gastrocnemius perform little net work, any increased work required to hop at faster speeds must be provided by other muscles. This is probably accomplished by the extensors of the hip and knee. It seems likely, therefore, that storage of elastic strain energy in the hindlimb tendons cannot be the entire explanation. If the economy of muscle force generation (ATP used/force generated) increased within the limb as a whole at faster hopping speeds, this might offset the increased cost associated with increases in force, rate and work that must occur at faster speeds. Such an increase in economy could be achieved by a shift in the dynamics of force generation within the limb to favor greater stretch activation of the fibers at faster hopping speeds. Alternatively, changes in the effective mechanical advantage (Biewener, 1989) of muscles acting at the knee and hip, for which direct measurements of force and length change are unavailable, might serve to lower the force-generating requirements of these larger muscle groups, offsetting the increase in energy expenditure that would otherwise be required at higher speed. Further studies are required to test these possibilities.

We thank M. Temaner and M. Sarre for their assistance in carrying out these experiments, D. Butler, D. Edyvean and G. Scott for assistance with electronic and mechanical equipment, J. Gilpin for machining the force buckle transducers and W. Corning, the Berkeley biomechanics seminar class and the referees for helpful comments on earlier drafts of the paper. Supported by NSF grant IBN-9306793 to A.A.B. and ARC grant A19332625 to R.V.B.

\section{References}

Alexander, R. McN. and Bennet-Clark, H. C. (1977). Storage of elastic strain energy in muscles and other tissues. Nature $\mathbf{2 6 5}$, 114-117.

Alexander, R. McN., Maloiy, G. M. O., Ker, R. F., Jayes, A. S. AND WARUI, C. N. (1982). The role of tendon elasticity in the locomotion of the camel (Camelus dromedarius). J. Zool., Lond. 198, 293-313.

Alexander, R. MCN. And Vernon, A. (1975). The mechanics of hopping by kangaroos (Macropodidae). J. Zool., Lond. 177, 265-303.

Basmajian, J. V. AND De LuCA, C. J. (1985). Muscles Alive: Their Functions Revealed by Electromyography. Baltimore: Williams and Wilkins. 561pp.

Baudinette, R. V., Snyder, G. K. and Frappell, P. B. (1992). Energetic cost of locomotion in the tammar wallaby. Am. J. Physiol. 262, R771-R778.

Bennett, M. B., Ker, R. F., Dimery, N. J. And AleXander, R. McN. (1986). Mechanical properties of various mammalian tendons. $J$. Zool., Lond. 209, 537-548. 


\section{A. A. Biewener, D. D. Konieczynski And R. V. Baudinette}

Bennett, M. B. AND TAYloR, G. C. (1995). Scaling elastic strain energy in kangaroos and the benefits of being big. Nature 378, $56-59$.

Biewener, A. A. (1989). Scaling body support in mammals: limb posture and muscle mechanics. Science 245, 45-48.

BIEWENER, A. A. (1998). Muscle-tendon stresses and elastic energy storage during locomotion in the horse. Comp. Biochem. Physiol. (in press).

Biewener, A. A. AND Baudinette, R. V. (1995). In vivo muscle force and elastic energy storage during steady-speed hopping of tammar wallabies (Macropus eugenii). J. exp. Biol. 198, 1829-1841.

Cavagna, G. A. and CitTerio, G. (1974). Effect of stretching on the elastic characteristics and the contractile component of frog striated muscle. J. Physiol., Lond. 239, 1-14.

Cavagna, G. A., Heglund, N. C. And Taylor, C. R. (1977). Mechanical work in terrestrial locomotion: two basic mechanisms for minimizing energy expenditures. Am. J. Physiol. 233, R243-R261.

DAWSON, T. J. AND TAYLOR, C. R. (1973). Energetic cost of locomotion in kangaroos. Nature 246, 313-314.

Dimery, N. J. AND AlEXANDER, R. MCN. (1985). Elastic properties of the hind foot of the donkey (Equus asinus). J. Zool., Lond. 207, 9-20.

Dimery, N. J., AleXAnder, R. McN. AND Ker, R. F. (1986a). Elastic extension of leg tendons in the locomotion of horses (Equus caballus). J. Zool., Lond. 210, 415-425.

Dimery, N. J., KeR, R. J. AND AleXANDER, R. MCN. (1986b). Elastic properties of the feet of deer (Cervidae). J. Zool., Lond. 208, 161-169.

Flitney, F. W. AND Hirst, D. G. (1978). Cross-bridge detachment and sarcomere 'give' during stretch of active frog's muscle. $J$. Physiol., Lond. 276, 449-465.

Goldman, D. E. And Hueter, T. F. (1956). Tabular data of the velocity and absorption of high frequency sound in mammalian tissues. J. acoust. Soc. Am. 28, 35-53.

Goldman, D. E. AND RichaRds, J. (1954). Measurements of highfrequency sound velocity in mammalian soft tissue. J. acoust. Soc. Am. 26, 981-983.

GRIFFITHS, R. I. (1987). Ultrasound transit time gives direct measurement of muscle fibre length in vivo. J. Neurosci. Meth. 21, 159-165.

GRIFFITHS, R. I. (1989). The mechanics of the medial gastrocnemius muscle in the freely hopping wallaby (Thylogale billardierii). $J$. exp. Biol. 147, 439-456.

GRIFFITHS, R. I. (1991). Shortening of muscle fibres during stretch of the active cat medial gastrocnemius muscle: the role of tendon compliance. J. Physiol., Lond. 436, 219-236.

Harry, J. D., Ward, A., Heglund, N. C., Morgan, D. L. AND McMahon, T. A. (1990). Cross-bridge cycling theories cannot explain high-speed lengthening behavior in muscle. Biophys. J. 57, 201-208.

Hatta, I., Sugi, H. And TAmura, Y. (1988). Stiffness changes in frog skeletal muscle during contraction recorded using ultrasonic waves. J. Physiol., Lond. 403, 193-209.

Heglund, N. C., Fedak, M. A., Taylor, C. R. and Cavagna, G. A. (1982). Energetics and mechanics of terrestrial locomotion. IV. Total mechanical energy changes as a function of speed and body size in birds and mammals. J. exp. Biol. 97, 57-66.

Heglund, N. C. AND TaYlor, C. R. (1988). Speed, stride frequency and energy cost per stride: how do they change with body size and gait? J. exp. Biol. 138, 301-318.

JosEPHSON, R. K. (1985). Mechanical power output from striated muscle during cyclical contraction. J. exp. Biol. 114, 493-512.

KER, R. F. (1981). Dynamic tensile properties of the plantaris tendon of sheep (Ovis aries). J. exp. Biol. 93, 283-302.

Ker, R. F., Bennett, M. B., Bibby, S. R., Kester, R. C. And AlexAnder, R. MCN. (1987). The spring in the arch of the human foot. Nature 325, 147-149.

Ker, R. F., Dimery, N. J. AND AleXANDER, R. McN. (1986). The role of tendon elasticity in hopping in a wallaby (Macropus rufogriseus). J. Zool., Lond. 208, 417-428.

KRAM, R. AND TAYLOR, C. R. (1990). Energetics of running: a new perspective. Nature 346, 265-267.

LoEB, G. E. AND GANS, C. (1986). Electromyography for Experimentalists. Chicago: University of Chicago Press. 373pp.

Loeb, G. E., Hoffer, J. A. AND Pratt, C. A. (1985). Activity of spindle afferents from cat anterior thigh muscles. I. Identification and patterns during normal locomotion. J. Neurophysiol. 54, 549-564.

Marsh, R. L., Olson, J. M. And GuZiK, S. K. (1992). Mechanical performance of scallop adductor muscle during swimming. Nature 357, 411-413.

Morgan, D. L., Proske, U. And Warren, D. (1978). Measurements of muscle stiffness and the mechanism of elastic storage of energy in hopping kangaroos. J. Physiol., Lond. 282, 253-261.

Rack, P. M. H. And Westbury, D. R. (1974). The short range stiffness of active mammalian muscle and its effect on mechanical properties. J. Physiol., Lond. 240, 331-350.

Roberts, T. J., Marsh, R. L., Weyand, P. G. and Taylor, C. R. (1997). Muscular force in running turkeys: the economy of minimizing work. Science 275, 1113-1115.

SHADWICK, R. E. (1990). Elastic energy storage in tendons: mechanical differences related to function and age. J. appl. Physiol. 68, 1033-1040.

Taylor, C. R., Heglund, N. C. And Maloiy, G. M. O. (1982). Energetics and mechanics of terrestrial locomotion. I. Metabolic energy consumption as function of speed and size in birds and mammals. J. exp. Biol. 97, 1-21. 